\section{MODEL COMPOUND STUDY OF THE PATHWAYS FOR AROMATIC HYDROCARBON FORMATION IN SOOT}

\author{
Nancy A. Tomczyk ${ }^{l}$, Jerry E. Hunt ${ }^{l}$, Randall E. Winans ${ }^{l}$, \\ Mark S. Solum ${ }^{2}$, Ronald J. Pugmire ${ }^{2}$, and Thomas H. Fletcher ${ }^{3}$
}

${ }^{1}$ Chemistry Division, Argonne National Laboratory, Argonne, IL 60439, navan@anl.gov; ${ }^{2}$ Dept. of Chemical and Fuels Engineering, University of Utah, Salt Lake City, UT 84112 ; ${ }^{3}$ Dept. of Chemical Engineering, Brigham Young University, Provo, UT 84602.

\section{Introduction}

To explore the mechanisms for formation of aromatic hydrocarbons as precursors to soot, a model system using combustion of biphenyl in a fuel rich flame is studied. The soots acquired at three different temperatures are solvent extracted and the extract characterized by both GCMS and high resolution mass spectrometry. A description of the NMR results for the whole soots has been published (1). The production of most products could be rationalized from the coupling of biphenyls and subsequent aromatic species and the addition of acetylenes to existing aromatic molecules. Early work by Badger on pyrolysis of hydrocarbons is used in developing these schemes (2). The reaction schemes to produce larger aromatic hydrocarbons will be discussed. Richter and Howard have discussed in detail potential reaction mechanisms in the formation of aromatics as precursors to soot (3).

\section{Experimental}

Soot samples from biphenyl are collected at three temperatures. Details on the samples are given in reference 1. The samples are extracted at room temperature with methylene chloride. Desorption electron impact high resolution mass spectra (DEIHRMS) are taken on a 3-sector MS-50 (4). Samples are heated on a probe from 200 to $700{ }^{\circ} \mathrm{C}$ at $200{ }^{\circ} \mathrm{C} / \mathrm{min}$. directly in the source. Precise mass measurements are averaged from scans over the entire temperature range. Formulae are assigned and the data sorted via a procedure developed in house. High resolution mass spectrometry data is sorted by both heteroatom content and by hydrogen deficiency, which is also termed double-bond equivalents (dbe). From hydrogen deficiency, the size of aromatic clusters can be estimated. GCMS data are obtained using a Hewlett Packard 6890 gas chromatograph with a 5973 quadrupole mass selective detector. The injection system is a CDS pyrolysis injector. The samples are placed in a quartz tube and the solvent is allowed to evaporate prior to analysis. The sample is pyrolyzed at $600^{\circ} \mathrm{C}$ while a stream of helium passed over the sample and onto the column. The column used is a 60 meter J\&W DB-17HT with a $0.25 \mathrm{~mm}$ id and a film thickness of 0.25 $\mu \mathrm{m}$. The oven is held at $40^{\circ} \mathrm{C}$ for 1 minute, then ramped at $6^{\circ} \mathrm{C} /$ minute to $280{ }^{\circ} \mathrm{C}$. It is held there for 10 minutes. The quadrupole is held at $150{ }^{\circ} \mathrm{C}$, and the source is at $230^{\circ} \mathrm{C}$.

\section{Results}

The structure and formation of the most abundant aromatic hydrocarbons (relative abundance $>10$ ) will be discussed. All of these species can be rationalized from the pyrolysis of biphenyl (1). Growth to larger molecules occurs by dimerization of aromatics and by acetylene addition. Both of these growth mechanisms have been suggested for soot formation. Analysis of these data suggest that both pathways are occurring along with a small amount of methylation and insertion of methylenes. The structures are deduced from the precursors and from molecular formulae. In some cases, especially in $\mathrm{C}_{2}$ addition, multiple isomers probably exist and a representation is shown. Only in the lowest temperature sample is biphenylene observed and is formed from the loss of two hydrogens. Biphenylene has been prepared in a high temperature plasma for biphenyl.

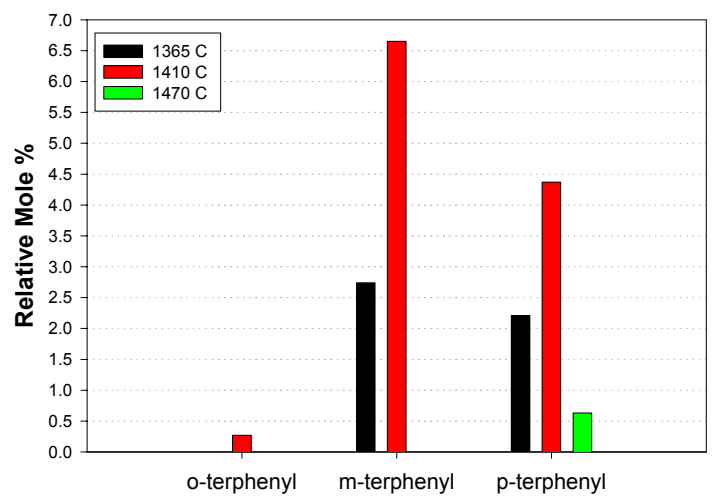

Figure 1. Distribution of terphenyl molecules from GCMS

All three isomers of terphenyl are observed in both GCMS (the data for the three temperatures are shown in Figure 1) and HRMS and result from the coupling of biphenyl with a benzene radical. Benzene radicals will form readily from cleavage of biphenyl. O-terphenyl [1] can be transformed simply by a loss of $\mathrm{H}_{2}$ to form triphenylene [2]. This terphenyl is found in the least amount of all three possible isomers in the $1410 \mathrm{~K}$ sample (Figure 1), which can be explained by its loss to triphenylene. The addition of acetylene $\left(\mathrm{C}_{2}\right)$ gives a benz[e]pyrene [3]. The addition of one more $\mathrm{C}_{2}$ results in benzo[ghi]perylene [4] and the next addition of $\mathrm{C}_{2}$ yields coronene [5]. In each of these cases only one isomer is possible and [1]-[4] have been identified by GCMS and the formulae for all five observed in HRMS.

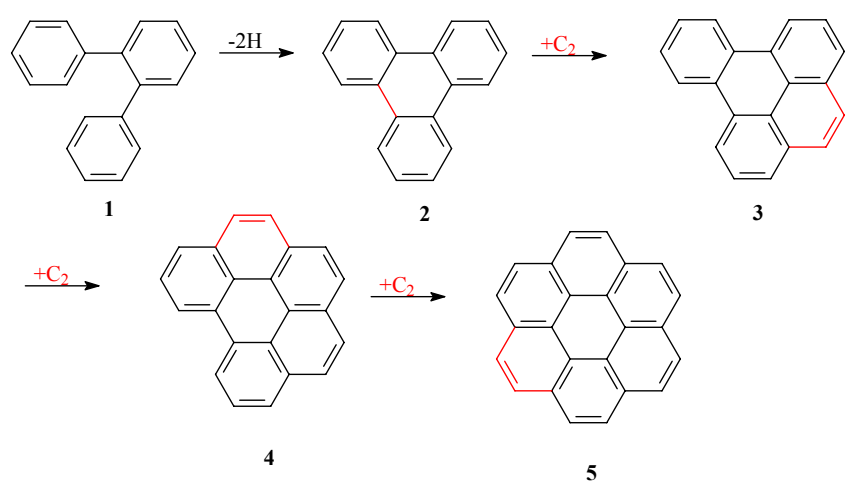

The m-terphenyl[6] gives a much different suite of products and does not yield molecules in the pyrene family. The addition of $\mathrm{C}_{2}$ gives a 
phenyl-phenanthrene [7] and with the addition of a second $\mathrm{C}_{2}$ is transformed into dibenz[a,j]anthracene [8]. This molecule [8] has been observed in soots in a number of studies (5). At the lower temperature (1365) two hydrogenated products, the 1,2-dihydro [9] and the 7,14-dihydro [10], are observed in the MS. These hydroaromatics appear not to survive at the higher temperatures.

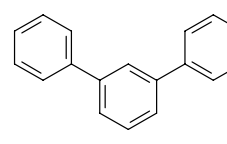

6

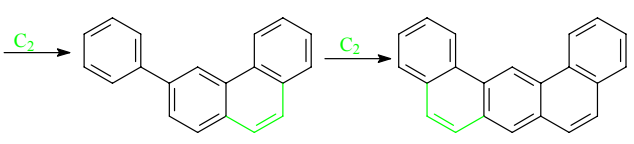

7

8

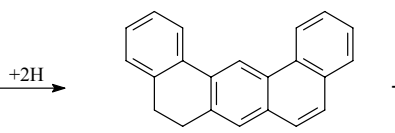

9

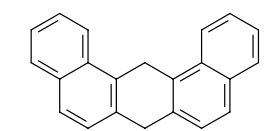

10
(5) Wornat, Mary J.; Ledesma, Elmer B.; Sandrowitz, Alyssa K.; Roth, Mark J.; Dawsey, Sanford M.; Qiao, You-Lin; Chen, Wen Environmental Science and Technology 2001, 35, 1943-1952.

(6) Krabiell, K.; Wanzl, W.; Juentgen, H. Coal Sci. Technol. 1987, 11(Int. Conf. Coal Sci., 1987), 687-90.

There are non-direct pathways to molecules such as perylene [11]. Under pyrolysis conditions the loss of $\mathrm{C}_{2}$ from phenanthrene to form biphenyl has been observed(6). Direct pathways from biphenyl to [11] are no readily apparent.

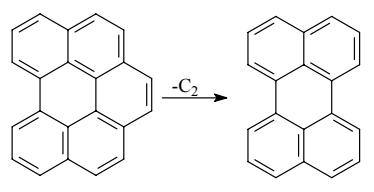

11

Larger PAHs are observed in the HRMS data, but structures can only be deduced from the smaller products characterized by GCMS and logical pathways that have been elucidated for their formation. For example, $\mathrm{C}_{32} \mathrm{H}_{16}$ which is found at the two higher temperatures could result from the dimerization of pyrene or the combination of pyrene with phenanthrene with the addition of $\mathrm{C}_{2}$.

\section{Conclusions}

This approach simplifies what is typically a very complex process in the formation of soot in flames. Reaction schemes can be developed which can be rationalized by the relatively simple product mix. Both aromatic coupling and the addition of acetylene appear to be important.

Acknowledgment. This work was performed under the auspices of the Office of Basic Energy Sciences, Division of Chemical Sciences, Geosciences, and Biosciences, U.S. Department of Energy, under contract number W-31-109-ENG-38.

\section{References}

(1) Solum, M. S.; Sarofim, A. F.; Pugmire, R. J.; Fletcher, T. H.; Zhang, H. Energy Fuels, 2001, 15, 961-971.

(2) Badger, G. M. Progr. Phys. Org. Chem., 1965, 3, 1-40.

(3) Richter, H.; Howard, J. B. Progress in Energy and Combustion

Science, 2000, 26, 565-608.

(4) Winans, R.E. In Advances in Coal Spectroscopy, H. L. C. Meuzelaar, Ed., Plenum Press: New York, 1992, pp. 141-164. 